\title{
Scanning Electron Microscopy of decayed tooth submitted to Er:YAG laser ablation
}

\author{
M. L. Redígolo, ${ }^{*}$ V. F. D. Gitirana, ${ }^{*}$ L. P. Alves, ${ }^{*}$ and E. Munin ${ }^{*}$ \\ *IP\&D, Univap, Av. Shishima Hifumi, 2911, São José dos Campos, SP, Brazil, 12244-000
}

The use of pulsed lasers in such applications as surgical tissue ablation has motivated investigative works to better understand the laser ablation mechanisms in several tissues types. An application for laser ablation that gains new adepts each year is its use for the removal of caries in dental tissue. [1] The traditional procedure to remove the decayed tissue is carried out by high speed air turbine handpiece which causes pain due to the vibration and a possible heating transmitted to the pulp. The use of the laser to the same procedure offers improvements to the patient perception [2].

In this in vitro study seventeen human molar teeth were used to evaluate the ablative effects of Er:YAG laser irradiation on dental tissue presenting occlusal caries. The samples were randomly divided into 3 groups ( 5 samples for each one) and were irradiated by an Er:YAG laser (571A model, BSL Tech. Inc.). The laser parameters used was $2940 \mathrm{~nm}$ wavelength, $10 \mathrm{~Hz}$ repetition rate and energy densities of $95 \mathrm{~J} / \mathrm{cm}^{2}, 127 \mathrm{~J} / \mathrm{cm}^{2}$ or $191 \mathrm{~J} / \mathrm{cm}^{2}$. The control group was represented by two samples: a decayed tooth and a healthy one removed for orthodontic purposes. The samples were analyzed under Scanning Electron Microscopy (SEM) at the Brazilian Synchrotron Light Laboratory to investigate the efficiency of the carie removal process. The electron microscopy were performed with a JSM-5900 LV microscope (JEOL) under $10 \mathrm{kV}$. All the samples received a thin layer of gold coating. The samples were also submitted to Energy Dispersive Spectroscopy (EDS) to differentiate the tissue on the bottom of the irradiated area from healthy or caried one.

The decayed tissue presented a branny aspect and a fibrous structure on the carie cavities, presenting a biofilm in some samples (figure 1a). We can observe the EDS results for this biofilm and how it differs from the EDS results for a sound dentin region (figure 2). The caries removal by laser under these experimental conditions were not completely efficient, depending on the energy density applied to the sample (see figure 1b). In this case, only the highest energy density used removed all the carie tissue. For the other energy densities applied the decayed tissue was still found after the laser ablation. The temperature on the pulp chamber was monitored during the experiments and the thermal damage threshold for the pulp $\left(5^{\circ} \mathrm{C}\right)$ was never reached for all samples. Due to the strong optical absorption at Er:YAG wavelength even the small amount of water found in hard tissue has a significant role in the laser-tissue interaction [3]. The ablation initialization process is the vaporization of the water increasing the pressure inside the tissue leading to local microexplosions that will cause the material ejection. The higher etch rates for carious material than sound material give efficiency removal of decay tissue and more control during sound dentin removal.

\section{References}

[1] L. Goldman, Nature 203, n. 4943 (1964) 417.

[2] H. E. Goodis et al., J. Dent. Res. 71 (1992) 162.

[3] A. F. Paghdiwala, M. Vaidyanathan and M. F. Paghdiwala, Scann. Microscop. 7 (1993) 989. 
a)

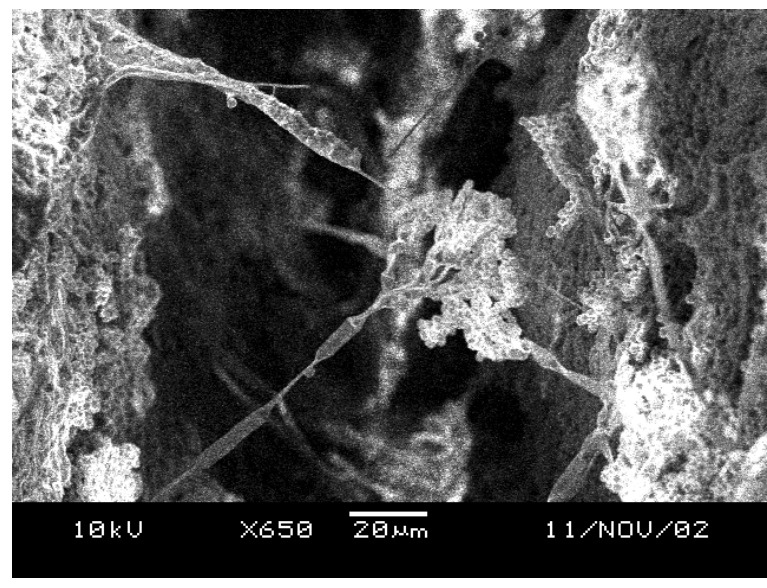

b)

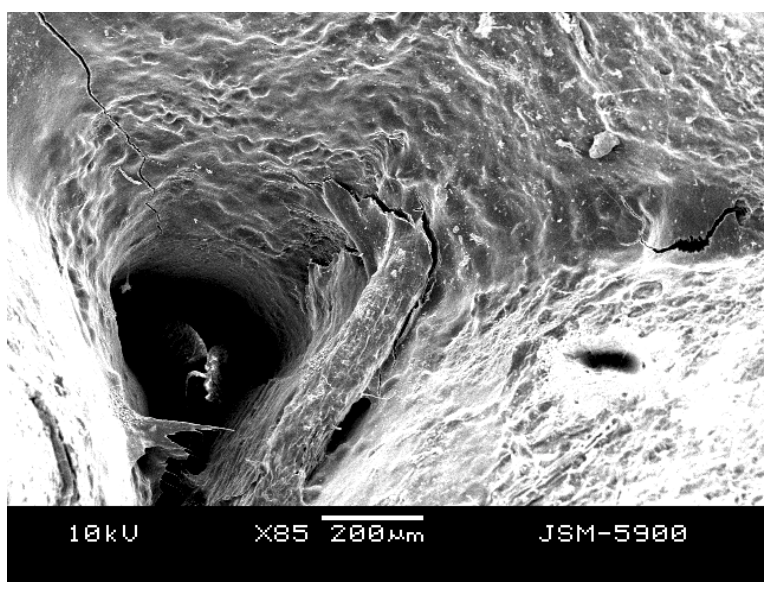

FIG. 1. (a) SEM micrograph of the biofilm inside a carie cavity $(10 \mathrm{kV}, \mathrm{x} 650,20 \mu \mathrm{m}$ bar); (b) SEM micrograph of the carie cavity irradiated with $127 \mathrm{~J} / \mathrm{cm}^{2}(10 \mathrm{kV}, \mathrm{x} 85,200 \mu \mathrm{m}$ bar);

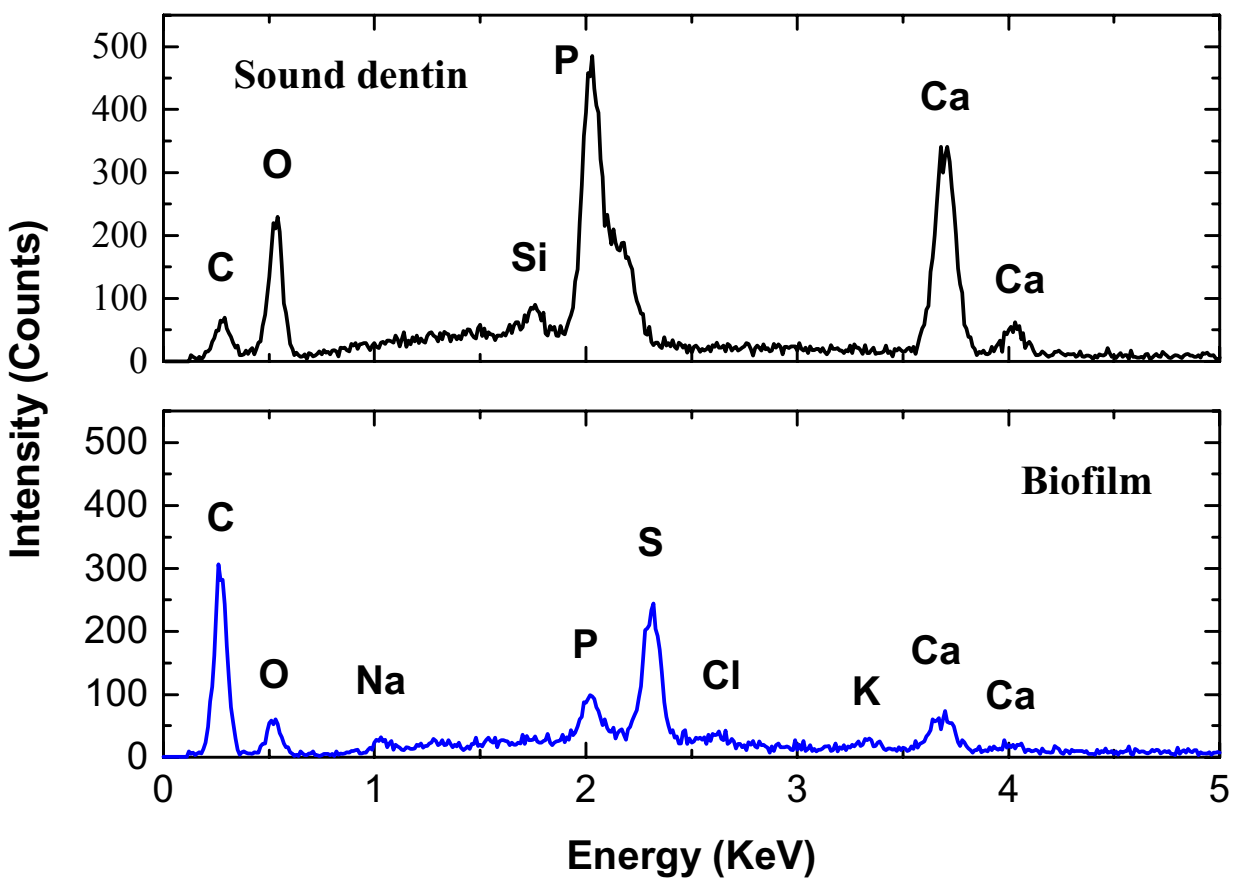

FIG. 2. EDS analysis of the sound dentin and the biofilm; 